\title{
Cytotoxic evaluation of a new ceramic-based root canal sealer on human fibroblasts
}

\author{
Sandra Chakar ${ }^{1}$, Sylvie Changotade ${ }^{2}$, Nada Osta ${ }^{3}$, Issam Khalil ${ }^{1}$
}

Correspondence: Dr. Sandra Chakar

Email: sandrachakar@gmail.com

\begin{abstract}
'Department of Endodontics, Faculty of Dentistry, Saint Joseph University, Beirut, Lebanon,

2UMR CNRS 7244, CSPBAT-Tissue Engineering, UFR SMBH, Paris 13 University, PRES Sorbonne Paris Cité, 74 Marcel Cachin, Bobigny 93017, France, ${ }^{3}$ Department of Prosthodontics, Faculty of Dentistry, Saint Joseph University, Beirut, Lebanon
\end{abstract}

\section{ABSTRACT}

Objectives: The purpose of this study was to evaluate the cytotoxicity of a new bioceramic-based root canal sealer (BioMM) by direct and indirect contact with human fibroblasts and to compare it with a zinc oxide-eugenol sealer, the Pulp Canal Sealer-extended working time (PCS-EWT). Materials and Methods: Cell viability was assessed through direct and indirect contact between human fibroblasts and sealer. Direct contact was performed at $24 \mathrm{~h}$, whereas the indirect contact was performed at 24 and $48 \mathrm{~h}$ at different concentrations: $100 \%, 50 \%$, and 25\%. After direct contact, 3-4,5-dimethylthiazol-2-yl)-2,5-diphenyltetrazolium bromide assay was used and the optical density was measured by a spectrophotometer. Giemsa stain was also performed for a qualitative evaluation of the cells. Statistical Analysis Used: Shapiro-Wilk test was used to verify the normality of distribution of the variable. Data were analyzed by analysis of variance and Tukey tests using SPSS for Windows software 18.0. The significance level used was $P<0.05$. Results: Direct contact showed a significantly higher cell viability with BioMM as compared to PCS-EWT $(P=0.002)$. Cell viability at $24 \mathrm{~h}$ was significantly higher with BioMM compared to PCS-EWT for the concentrations of 50\% $(P=0.004)$ and $25 \%(P=0.003)$, whereas no significant difference was noted at $100 \%(P=0.141)$. Cell viability at $48 \mathrm{~h}$ was significantly higher with BioMM as compared to PCS-EWT at $25 \%(P=0.007)$. No significant difference was observed at $100 \%(P=0.484)$ and $50 \%(P=0.185)$. Conclusion: BioMM may be considered minimally cytotoxic if accidentally extruded into the periapical tissues.

Key words: 4,5-dimethylthiazol-2-yl)-2,5-diphenyltetrazolium bromide, bioceramic, cell viability, sealer

\section{INTRODUCTION}

The aim of the endodontic treatment is to clean, shape, and disinfect the root canal system to fill it and block all ports of entry of bacteria, for long-term success. ${ }^{[1,2]}$ Gutta-percha is the material of choice used to obturate root canals, but it shrinks upon cooling and lacks chemical adhesion to canal wallss. ${ }^{[3]}$ Recently, new bioceramic-based materials (Mainly composed of tricalcium silicate) were introduced to the market as root canal sealers. According to the manufacturers,

\begin{tabular}{|l|l|}
\hline \multicolumn{2}{|c|}{ Access this article online } \\
\hline Quick Response Code: \\
\hline
\end{tabular}

bioceramics show alkaline $\mathrm{pH}$, antibacterial activity, radiopacity, and biocompatibility and are able, during the setting process, to form hydroxyapatite and ultimately a bond between dentin and filling material. ${ }^{[3,4]}$

Obturation with a bioceramic root canal sealer consists of fitting a gutta-percha master cone that corresponds to the size of the last instrument used for cleaning. The cone is coated with the sealer and placed slowly

This is an open access article distributed under the terms of the Creative Commons Attribution-NonCommercial-ShareAlike 3.0 License, which allows others to remix, tweak, and build upon the work non-commercially, as long as the author is credited and the new creations are licensed under the identical terms.

For reprints contact: reprints@medknow.com

How to cite this article: Chakar S, Changotade S, Osta N, Khalil I. Cytotoxic evaluation of a new ceramic-based root canal sealer on human fibroblasts. Eur J Dent 2017;11:141-8.

DOI: 10.4103/ejd.ejd_2_17 
to working length and then cut at the orifice with a heated carrier. This will carry sufficient material to seal the apex. ${ }^{[4]}$

A novel bioceramic-based root canal sealer (powder and liquid) was elaborated by Khalil and Naaman at Saint Joseph University, Lebanon. It is composed of tricalcium silicate, calcium carbonate, and a radiopacifier, tantalum oxide. The powder is obtained by a sol-gel method that consists of producing pure materials from small molecules. It has been reported that materials prepared by a sol-gel process are more bioactive than materials of the same composition prepared by other methods. ${ }^{[5-7]}$

Although root canal sealers are designed to be confined to the root canal system, they can sometimes be extruded into the periapical tissues. Thus, their biocompatibility is essential to evaluate..$^{[8-10]}$

The aim of the study was to evaluate the cytotoxicity of a new bioceramic-based root canal sealer (BioMM) by direct and indirect contact with human fibroblasts and to compare it with a zinc-oxide-eugenol sealer, Pulp Canal Sealer-extended working time (PCS-EWT), at 24 and $48 \mathrm{~h}$.

\section{MATERIALS AND METHODS}

\section{Primary cell cultures}

Human dermal fibroblasts were cultured in $75 \mathrm{~cm}^{2}$ flasks containing Dulbecco's modified Eagle medium (DMEM), supplemented with $10 \%$ fetal bovine serum, $100 \mathrm{mg} / \mathrm{mL}$ penicillin, and $100 \mu \mathrm{L} / \mathrm{ml}$ streptomycin (supplemented DMEM). Cultures were maintained at $37^{\circ} \mathrm{C}$ in a humidified incubator under ambient pressure air atmosphere containing $5 \% \mathrm{CO}_{2}$. Confluent cell monolayers were trypsinized (ethylenediaminetetraacetic acid-trypsin), and harvested cells were used for cytotoxicity experiments:

- 60,000 cells / $\mathrm{ml}$ for the direct cytotoxic evaluation

- 100,000 cells $/ \mathrm{ml}$ for the 96-well plates

- 40,000 cells/ml for the 24-well plates (used for Giemsa staining).

The plates were left in the incubator for $24 \mathrm{~h}$ at $37^{\circ} \mathrm{C}$ and $5 \% \mathrm{CO}_{2}$.

\section{Direct contact between the cells and sealers}

We obtained the sealers from the manufacturers and the sealers were prepared according to their instructions under aseptic conditions (PCS-EWT was mixed with eugenol whereas BioMM with sterile distilled water).

The freshly mixed sealers were placed in direct contact with the fibroblasts for $24 \mathrm{~h}$ at $37^{\circ} \mathrm{C}$ and $5 \% \mathrm{CO}_{2}$ (two wells for the PCS-EWT, three wells for the BioMM, three control groups [only cells and DMEM], and one positive control group with diisocyanate, a toxic substance for the cells).

Cells were stained with Giemsa for qualitative evaluation under an optical microscope.

\section{Indirect contact between the cells and sealers}

The sealers were mixed and placed in the incubator for $1 \mathrm{~h}$ at $37^{\circ} \mathrm{C}$ and $5 \% \mathrm{CO}_{2}$ before adding supplemented DMEM in a way to obtain $0.1 \mathrm{~g}$ of sealer in $1 \mathrm{ml}$ of DMEM (ISO-10993-5) and then incubated for $24 \mathrm{~h}$. After that, we performed the cytotoxic evaluation at various dilutions of the extracts $(100 \%, 50 \%$, and $25 \%$ ).

Cells were stained with Giemsa for evaluation qualitative under the optical microscope.

\section{4,5-Dimethylthiazol-2-yl)-2,5-diphenyltetrazolium bromide assay}

The $\quad 4,5-\mathrm{d}$ i methylthiazol-2-y l) - 2,5diphenyltetrazolium bromide (MTT) assay focuses on the capacity of mitochondrial dehydrogenase enzymes present in the living cells to convert the yellow watersoluble tetrazolium salt 3-(4,5-dimethylthiazol-1yl),2,5-diphenyl tetrazolium bromide into purple formazan crystals. These crystals are insoluble and stocked in the cytoplasm of cells. The number of viable cells is thus directly proportional to the formazan product formed.

After 24 or $48 \mathrm{~h}$, the culture medium was removed and was replaced by:

- Extract mediums (100\%, 50\%, and 25\%)

- Supplemented DMEM for the control group

- Diisocyanate for the positive control group.

The plates were left in the incubator for 24 or $48 \mathrm{~h}$ before the cytotoxicity evaluation was carried out.

After each incubation time, an MTT solution at $0.5 \mathrm{mg} / \mathrm{ml}$ was prepared and added to each well to be tested for $2 \mathrm{~h}$, then the purple formazan was dissolved using dimethyl sulfoxide, and the absorbance was measured at $570 \mathrm{~nm}$ using a spectrophotometer (Bio-Rad, SmartSpec Plus, USA).

Each condition was done in a triplicate. 
Cell viability was calculated using:

$\%$ viability $=\frac{\text { mean OD of treated cells }}{\text { meanOD of control cells }} \times 100$

Cytotoxic responses were rated as severe $(30 \%)$, moderate $(30 \%-60 \%)$, slight $(60 \%-90 \%)$, or noncytotoxic (>90\%).

\section{Statistical analysis}

Shapiro-Wilk test was used to verify the normality of distribution of the variable.

Data were statistically analyzed by analysis of variance and Tukey tests using SPSS for Windows software 18.0 (IBM Corporation, New York, USA). The significance level used was $P<0.05$.

Data are expressed as means \pm standard deviation.

\section{RESULTS}

\section{Direct contact between human fibroblasts and cements}

After direct contact period between human fibroblasts and the cements, cell viability was significantly higher with BioMM when compared to PCS-EWT $(P=0.002)$ [Table 1 and Graph 1].

As shown in Figure 1a, untreated cells were spindle-shaped with flattened extended cellular processes. After exposure to PCS-EWT for $24 \mathrm{~h}$, the fibroblasts were retracted with residual cytoskeleton [Figure 1c]. No marked morphological changes were observed when in contact with BioMM [Figure 1e and f]. Figure $1 \mathrm{~b}$ shows the morphology of the fibroblasts in contact with diisocyanate.

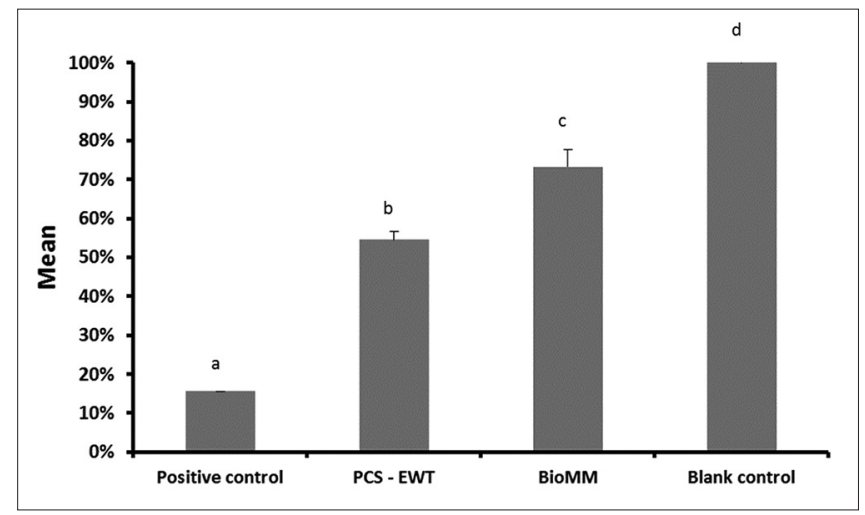

Graph 1: Mean and standard deviation of cell viability at $24 \mathrm{~h}$. Same letters indicate no significant difference between groups according to Tukey honest significant difference post hoc comparisons $(P>0.05)$. Different letters indicate a significant difference between groups according to Tukey honest significant difference post hoc comparisons $(P<0.05)$

\section{Indirect contact between fibroblasts and cements} at $24 \mathrm{~h}$

Comparison of cell viability between the groups at $24 \mathrm{~h}$

Mean and standard deviation of cell viability at $24 \mathrm{~h}$ are presented in Table 2 and Graphs 2, 3.

Cell viability was significantly higher for the BioMM $25 \%$, intermediate with BioMM 50\%, and low with BioMM $100 \%(P<0.001)$. Tukey test showed a significant difference between BioMM 25\% and the untreated cells (blank control).

No significant difference was observed when comparing cell viability with PCS-EWT at $25 \%, 50 \%$, and $100 \%(P=0.766)$.

Comparison between BioMM and Pulp Canal Sealer-extended working time at $24 \mathrm{~h}$

Cell viability at $24 \mathrm{~h}$ was significantly higher with BioMM compared to PCS-EWT for the concentrations of $50 \%(P=0.004)$ and $25 \%(P=0.003)$.

No significant difference was observed between BioMM and PCS-EWT at $100 \%(P=0.141)$ [Table 3, Figure 2, and Graph 4].

Comparison of cell viability between the groups at $48 \mathrm{~h}$ Mean and standard deviation of cell viability at $48 \mathrm{~h}$ are presented in Table 4 and Graphs 5, 6.

\begin{tabular}{|c|c|c|c|}
\hline & $n$ & Mean $\pm S D(\%)$ & Toxicity \\
\hline PCS-EWT & 2 & $54.58 \pm 2.16^{b}$ & Moderately cytotoxic \\
\hline BioMM & 3 & $73.03 \pm 4.29 c$ & Slightly cytotoxic \\
\hline Blank control & 3 & $100.0 \pm 3.64^{d}$ & Noncytotoxic \\
\hline Positive control & 1 & $15.65^{a}$ & Cytotoxic \\
\hline
\end{tabular}

$a, b, c$ and $d$ in the table are the same one as in the Graph 1. PCS: Pulp Canal Sealer, EWT: Extended working time, SD: Standard deviation

Table 2: Cell viability for BioMM and Pulp Canal Sealer-extended working time at $24 \mathrm{~h}$

\begin{tabular}{lccl}
\hline Cell viability at $\mathbf{2 4} \mathbf{h}$ & $\boldsymbol{n}$ & Mean \pm SD $(\%)$ & Interpretation \\
\hline Blank control & 3 & $100.0 \pm 0.0$ & Noncytotoxic \\
PCS-EWT 100\% & 3 & $77.9 \pm 8.3$ & Slightly cytotoxic \\
PCS-EWT 50\% & 3 & $80.0 \pm 2.1$ & Slightly cytotoxic \\
PCS-EWT 25\% & 3 & $82.1 \pm 2.9$ & Slightly cytotoxic \\
BioMM100\% & 3 & $87.2 \pm 3.1$ & Slightly cytotoxic \\
BioMM 50\% & 3 & $90.7 \pm 2.2$ & Noncytotoxic \\
BioMM 25\% & 3 & $96.3 \pm 2.4$ & Noncytotoxic \\
Positive control & 3 & $64.9 \pm 4.3$ & Moderately cytotoxic
\end{tabular}

PCS: Pulp Canal Sealer, EWT: Extended working time, SD: Standard deviation 
Cell viability was not significantly different between BioMM 25\%, BioMM 50\%, BioMM 100\%, and the blank control $(P=0.970)$.

Cell viability was not significantly different between PCS-EWT 25\%, PCS-EWT 50\%, PCS-EWT 100\%, and the blank group $(P=0.723)$.

\section{Comparison between BioMM and Pulp Canal} Sealer-extended working time at $48 \mathrm{~h}$

Cell viability at $24 \mathrm{~h}$ was significantly higher with BioMM compared to PCS-EWT at 25\% $(P=0.007)$.

\begin{tabular}{|c|c|c|c|}
\hline \multirow[t]{2}{*}{ Concentration (\%) } & \multicolumn{3}{|c|}{ Cell viability at $24 \mathrm{~h}$} \\
\hline & PCS-EWT (\%) & BioMM (\%) & $P$ \\
\hline 100 & $77.9 \pm 8.3$ & $87.2 \pm 3.1$ & 0.141 \\
\hline 50 & $80.0 \pm 2.1$ & $90.7 \pm 2.2$ & 0.004 \\
\hline 25 & $82.1 \pm 2.9$ & $96.3 \pm 2.4$ & 0.003 \\
\hline
\end{tabular}

PCS: Pulp Canal Sealer, EWT: Extended working time
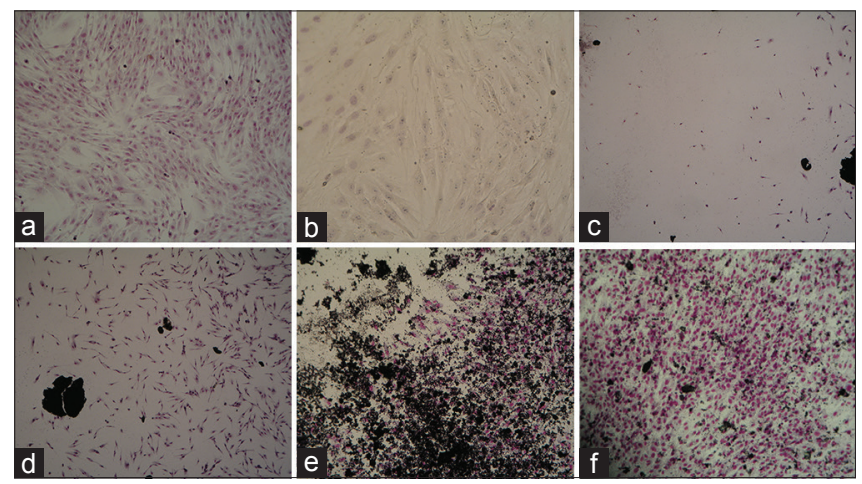

Figure 1: (a) Blank control. (b) Positive control with diisocyanate. (c) Fibroblasts in contact with Pulp Canal Sealer-extended working time (proximal). (d) Fibroblasts in contact with Pulp Canal Sealer-extended working time (distal). (e) Fibroblasts in contact with BioMM (proximal). (f) Fibroblasts in contact with BioMM (distal)
No significant difference was observed between BioMM and PCS-EWT at $100 \%(P=0.484)$ and $50 \%$ $(P=0.185)$ [Table 5, Figure 3 and Graph 7].

\section{DISCUSSION}

It is of utmost importance that root canal sealers have acceptable biocompatibility because they come in contact with soft and hard tissues apically. ${ }^{[11]}$

The aim of this study was to evaluate the cytotoxicity of BioMM, a new bioceramic-based sealer, and PCS-EWT, a zinc oxide-eugenol sealer, ${ }^{[12]}$ using different concentration extracts on human fibroblasts. Cell viability was assessed using MTT assay, and Giemsa staining was used for a qualitative evaluation of the cells using an optical microscope.

All sealers exhibited some sort of cytotoxicity when freshly mixed; however, their cytotoxicity is reduced after setting. Our study showed that BioMM is significantly less toxic than PCS-EWT when freshly mixed and in direct contact with human fibroblasts (73\% cell viability for BioMM and $54 \%$ cell viability for PCS-EWT). Our results are in concordance with those of Camps et al., who compared PCS-EWT with a new bioceramic sealer, BioRoot RCS (Septodont, France) of similar composition to the BioMM. The powder is composed of tricalcium silicate with a radiopacifier, tantalum oxide, and sodium carbonate incorporated into the formula to accelerate the setting of the sealer. The powders are synthesized in laboratories from highly pure raw materials. These "hydraulic" cements set in moisture and have good biological properties. Recently, they were commercialized as root canal sealers and many studies showed their potential to create a layer of calcium phosphate/apatite when immersed in biological fluids. ${ }^{[13-15]}$
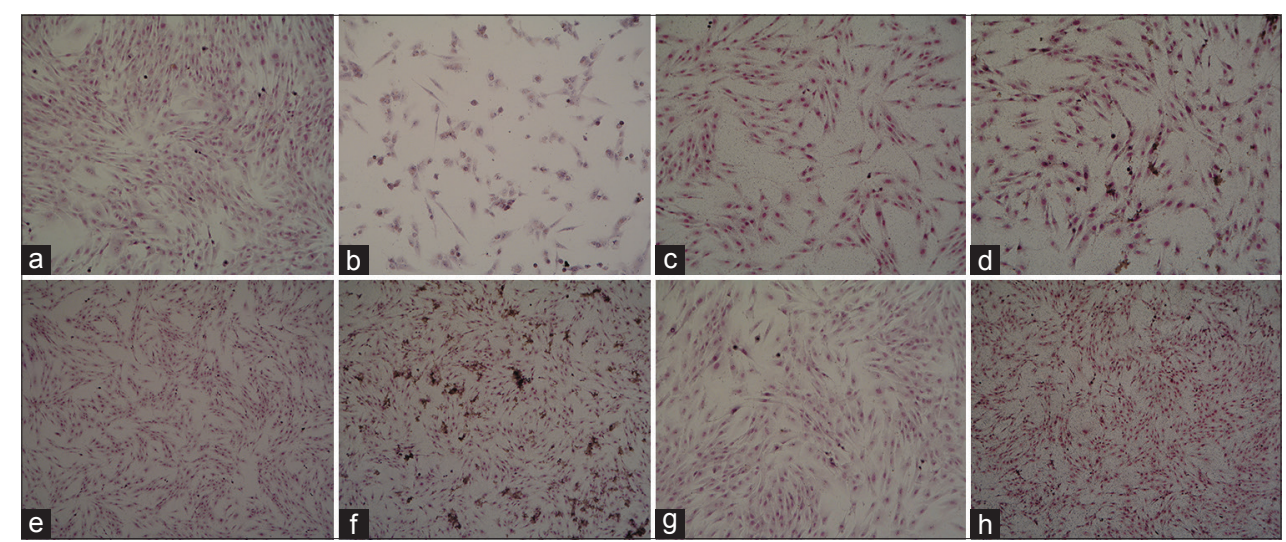

Figure 2: (a) Blank control. (b) Positive control. (c) Pulp Canal Sealer-extended working time 100\%. (d) BioMM 100\%. (e) Pulp Canal Sealer-extended working time 50\%. (f) BioMM 50\%. (g) Pulp Canal Sealer-extended working time 25\%. (h) BioMM 25\% 


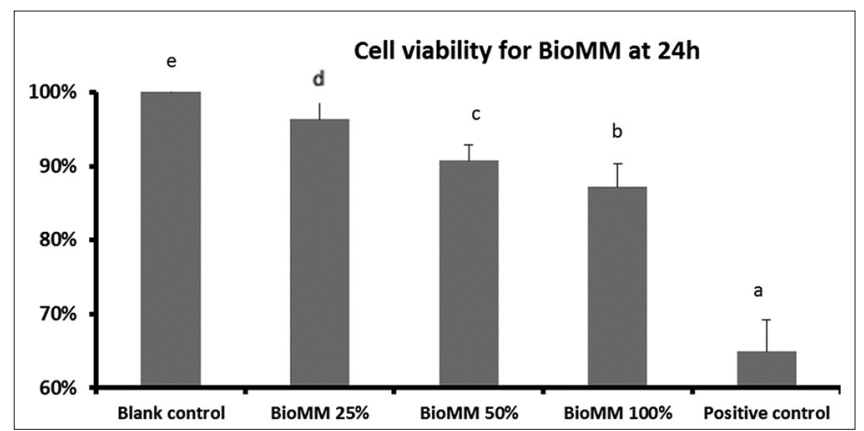

Graph 2: Cell viability for BioMM at $24 \mathrm{~h}$. Same letters indicate no significant difference between groups according to Tukey honest significant difference post hoc comparisons $(P>0.05)$. Different letters indicate a significant difference between groups according to Tukey honest significant difference post hoc comparisons $(P<0.05)$

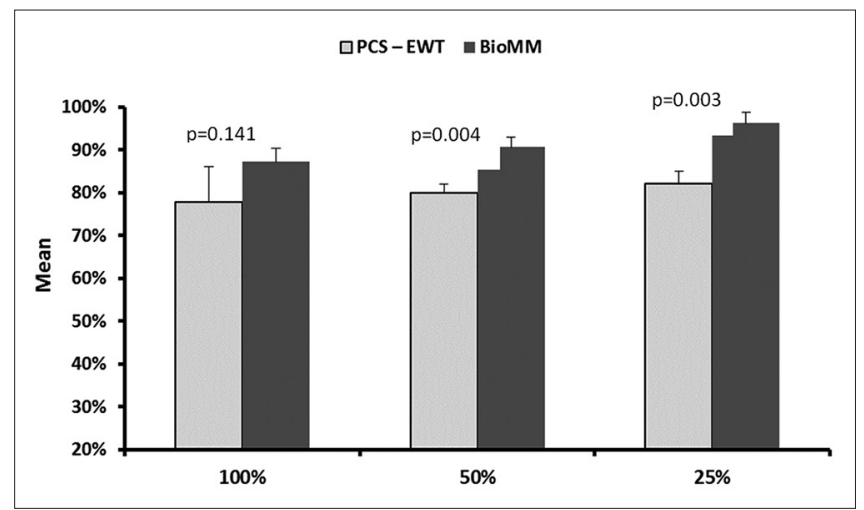

Graph 4: Comparison between Pulp Canal Sealer-extended working time and BioMM at $24 \mathrm{~h}$

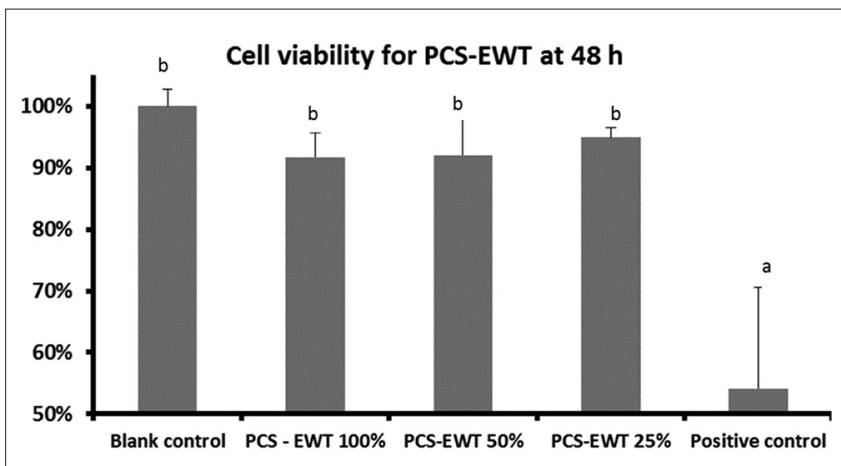

Graph 6: Cell viability for Pulp Canal Sealer-extended working time at $48 \mathrm{~h}$. Same small letter indicate no significant difference between groups according to Tukey honest significant difference post hoc comparisons $(P>0.05)$. Different small letters indicate a significant difference between groups according to Tukey honest significant difference post hoc comparisons $(P<0.05)$

The cytotoxicity of PCS-EWT is probably due to eugenol in its composition, whose presence was demonstrated toxic depending on its concentration in multiple studies, in particular that of Abou Hashieh and Ho, who investigated the quantity of eugenol released from teeth obturated using this sealer and found that the amount of eugenol decreased with

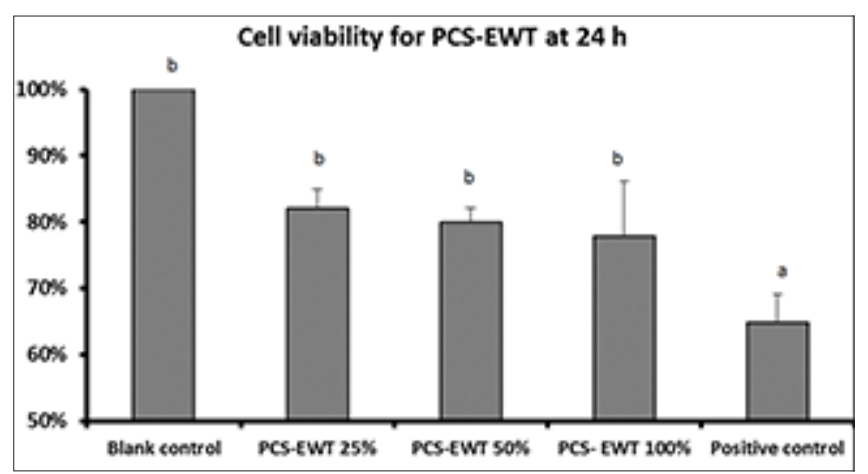

Graph 3: Cell viability for Pulp Canal Sealer-extended working time at $24 \mathrm{~h}$. Same small letter indicate no significant difference between groups according to Tukey honest significant difference post hoc comparisons $(P>0.05)$. Different small letters indicate a significant difference between groups according to Tukey honest significant difference post hoc comparisons $(P<0.05)$

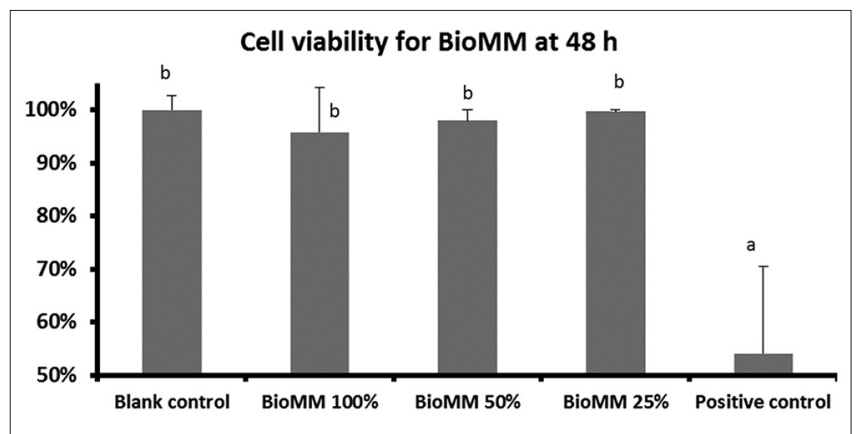

Graph 5: Cell viability of BioMM 48 h. Same small letter indicate no significant difference between groups according to Tukey honest significant difference post hoc comparisons $(P>0.05)$. Different small letters indicate a significant difference between groups according to Tukey honest significant difference post hoc comparisons $(P<0.05)$

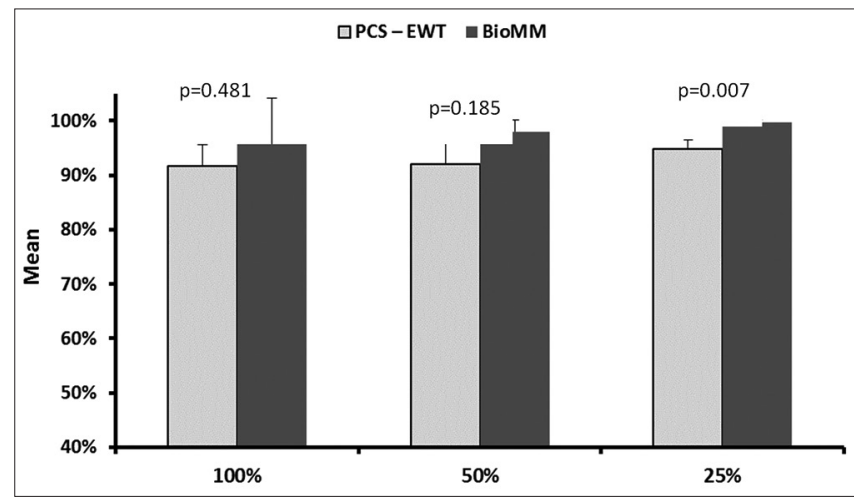

Graph 7: Comparison between Pulp Canal Sealer-Extended working time and BioMM $48 \mathrm{~h}$

time and that its toxicity was dose-dependent. In fact, the biological effects of eugenol vary greatly in terms of concentration: Eugenol may have beneficial effects in minimal concentrations (production of prostaglandins, nervous activity) but may be cytotoxic for concentrations above $10^{-3} \mathrm{M}$ and cause cellular death and/or inhibit cellular growth. ${ }^{[16,17]}$ The ISO 

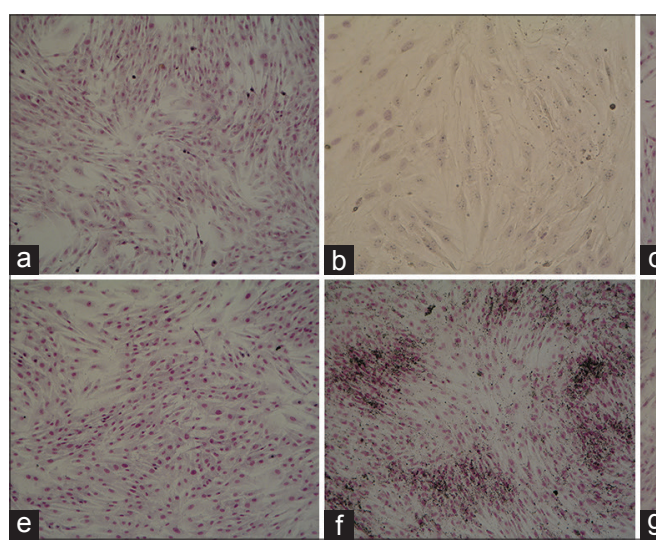
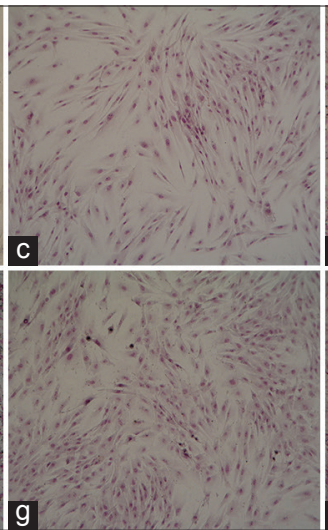

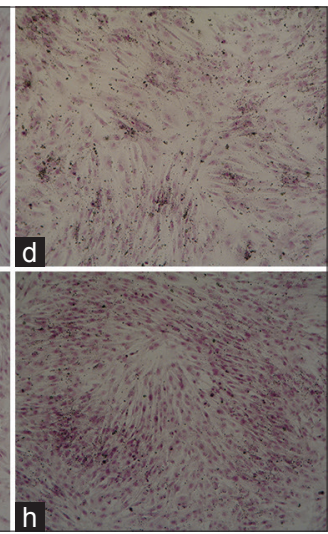

Figure 3: (a) Blank control. (b) Positive control. (c) Pulp Canal Sealer-extended working time $100 \%$. (d) BioMM 100\%. (e) Pulp Canal Sealer-extended working time 50\%. (f) BioMM 50\%. (g) Pulp Canal Sealer-extended working time 25\%. (h) BioMM 25\%

\begin{tabular}{lcccc}
\multicolumn{6}{l}{ Table 4: Cell viability for BioMM and Pulp Canal Sealer-extended working time at $\mathbf{4 8} \mathbf{h}$} \\
\hline Cell viability at $\mathbf{4 8} \mathbf{h}(\%)$ & $\boldsymbol{n}$ & Moyenne (\%) & Écart-type (\%) & Interprétation \\
\hline Blank control & 3 & 100.0 & 2.7 & Noncytotoxic \\
PCS-EWT 100\% & 3 & 91.7 & 4.0 & Noncytotoxic \\
PCS-EWT 50\% & 3 & 92.0 & 6.1 & Noncytotoxic \\
PCS-EWT 25\% & 3 & 94.9 & 1.6 & Noncytotoxic \\
BioMM 100\% & 3 & 95.8 & 8.4 & Noncytotoxic \\
BioMM 50\% & 3 & 98.0 & 2.1 & Noncytotoxic \\
BioMM 25\% & 3 & 99.7 & 16.4 & Noncytotoxic \\
Positive control & 3 & 54.1 & & Moderately cytotoxic \\
\hline PCS: & & &
\end{tabular}

\begin{tabular}{lccc} 
Table 5: Comparison of cell viability between BioMM \\
and Pulp Canal Sealer-extended working time at $\mathbf{4 8 ~} \mathbf{~ h}$ \\
\hline Concentrations (\%) & \multicolumn{4}{c}{ Cell viability at $\mathbf{4 8} \mathbf{~ h}$} \\
\cline { 2 - 4 } & PCS-EWT (\%) & BioMM (\%) & $\boldsymbol{P}$ \\
\hline 100 & $91.7 \pm 4.0$ & $95.8 \pm 8.4$ & 0.481 \\
50 & $92.0 \pm 6.1$ & $98.0 \pm 2.1$ & 0.185 \\
25 & $94.9 \pm 1.6$ & $99.7 \pm 0.4$ & 0.007 \\
\hline
\end{tabular}

PCS: Pulp Canal Sealer, EWT: Extended working time

10993-5 standards for testing product cytotoxicity require to fill $1 / 10^{\text {th }}$ of the surface well that means $250 \mathrm{~mm}^{2} / \mathrm{ml}$, which means that the contact is greater between the sealer and the cells. This may lead to an overestimation of the cytotoxicity of sealers. ${ }^{[14]}$

Regarding the indirect cytotoxicity at $24 \mathrm{~h}$, our results showed that cell viability was significantly higher with BioMM compared with PCS-EWT at 50\% and $25 \%$, whereas at $100 \%$, no significant difference was noted. At $48 \mathrm{~h}$, cell viability was significantly higher with BioMM compared with PCS-EWT at $100 \%$ and not significant for at $25 \%$ and $50 \%$.

Although it is impossible to determine exactly the quantity of sealer extruded from the foramina, cytotoxic evaluation at different concentrations was performed since periapical tissues are in contact with sealers. ${ }^{[17,18]}$ Substances released by the sealer decrease with the setting of the material and the continuous elimination of the extracellular fluids. Furthermore, only qualitative evaluation of the cells was made because the micrographs taken only show their attachment qualitatively, but for future research, cell proliferation assays such as picogreen DNA assays or bicinchoninic acid protein assays will be interesting to perform with longer exposures to the bioceramic material.

Our results may not corroborate with many studies that showed high cytotoxicity for PCS-EWT for up to several weeks. ${ }^{[9,18-20]}$ The results show that the time of extraction was at $60 \mathrm{~min}$, and according to the manufacturer, the time of setting of PCS-EWT is between 60 and $120 \mathrm{~min}$. This short setting time may explain the biocompatibility obtained since there might not have been enough degradation products in the culture medium. In addition, the different experimental methods and designs for each study may be the cause for the divergent results. Yilmaz et al. investigated the cytotoxicity of many sealers including PCS-EWT and found high cytotoxicity at $25 \%$ and $50 \%$, but they did not mention the quantity of 
sealer used - which should be $0.1 \mathrm{~g}$ of product per milliliter (ISO 10993-5).

The type of cells used may also explain the diversity of the results obtained. There is a difference between cells issued from primary culture (directly sampled from an organism) and cell lines (homogenous population of cells more standardized than primary cells and offer more reproducible results). ${ }^{[21,22]}$

A study by Berridge et al. indicated that different sensitivity responses exist as a response to a test of dehydrogenase reduction (such as MTT and 2,3-Bis-(2-Methoxy-4-Nitro-5-Sulfophenyl)-2HTetrazolium-5-Carboxanilide (XTT)); the responses are cell-dependent. These methods do not evaluate the same enzyme systems and there is evidence that reduction using MTT is not only associated with mitochondrial activity but also associated with the cytoplasm and the nonmitochondrial membranes that include the endosome/lysosome and the cell membrane. ${ }^{[20,23]}$

Our results show a minor cytotoxicity for the bioceramic sealer with a cell viability higher than $90 \%$. Previous studies about tricalcium-based sealers also showed favorable responses, and it was shown that they were potentially bioactive, preserved the osteo-odontogenic properties of pulpal stem cells, minimally irritating for the tissues, and do not interfere with bone regeneration if they were accidentally extruded through the foramina. ${ }^{[10,24,25]}$

Research using cellular models is popular for in vitro testing but has important limitations. Most of them are represented with only one type of cells; therefore, the interaction between different types of cells is inexistent and the conditions of the culture are not homeostatic. All these mechanisms are not present in the wells and must be taken into consideration when interpreting the results of the cytotoxic evaluations. For example, most of the cytotoxic evaluations in vitro show high toxicity for PCS-EWT, whereas a study of subcutaneous implantation in the connective tissue of rats for the same product showed better tissue organization than AH-Plus. Furthermore, Cotton et al. did a retrospective study to compare clinical results after obturation with Resilon/Epiphany and Gutta-percha/Kerr Sealer and did not find any detectable difference in the results evaluated by periapical index and clinical symptoms. ${ }^{[19,26]}$

Tricalcium silicate-based sealers offer a new perspective in obturation and may have better sealing ability compared to others sealers. Our results showed that BioMM may be considered as minimally cytotoxic if accidentally extruded through the apical constriction. However, given all the limitations of the in vitro studies, caution must be used when conclusions are drawn from the results. Further studies, in vivo and in vitro, are required to make sure of the absence of cytotoxicity for dental materials.

\section{Financial support and sponsorship}

Nil.

\section{Conflicts of interest}

There are no conflicts of interest.

\section{REFERENCES}

1. Hülsmann M, Peters O, Dummer P. Mechanical preparation of root canals: Shaping goals, techniques and means. Endod Topics 2005;10:30-76.

2. Johnson WT, Kulild J. Obturation of the cleaned and shaped root canal system. In: Cohen's Pathways of the Pulp. $10^{\text {th }}$ ed. Annapolis, Maryland: Mosby Elsevier; 2011. p. 349-88.

3. Candeiro GT, Correia FC, Duarte MA, Ribeiro-Siqueira DC, Gavini G. Evaluation of radiopacity, $\mathrm{pH}$, release of calcium ions, and flow of a bioceramic root canal sealer. J Endod 2012;38:842-5.

4. Koch K, Brave D. Bioceramic technology - The game changer in endodontics. Endod Pract 2009;3:13-6.

5. Formosa LM, Mallia B, Bull T, Camilleri J. The microstructure and surface morphology of radiopaque tricalcium silicate cement exposed to different curing conditions. Dent Mater 2012;28:584-95.

6. Chen CC, Ho CC, David Chen CH, Ding SJ. Physicochemical properties of calcium silicate cements for endodontic treatment. J Endod 2009;35:1288-91.

7. Vallet-Regí M. Bioceramics. In: Bioceramics with Clinical Applications. Ch. 1. Chichester: John Wiley \& Sons; 2014. p. 3-15.

8. Dahl J. Toxicity of endodontic filling materials. Endod Topics 2005;12:39-43.

9. Da Silva PT, Pappen FG, Souza EM, Dias JE, Bonetti Filho I, Carlos IZ, et al. Cytotoxicity evaluation of four endodontic sealers. Braz Dent J 2008;19:228-31.

10. Camps J, Jeanneau C, El Ayachi I, Laurent P, About I. Bioactivity of a calcium silicate-based endodontic cement (BioRoot RCS): Interactions with human periodontal ligament cells in vitro. J Endod 2015;41:1469-73.

11. Tai KW, Huang FM, Chang YC. Cytotoxic evaluation of root canal filling materials on primary human oral fibroblast cultures and a permanent hamster cell line. J Endod 2001;27:571-3.

12. Khalil I, Naaman A, Camilleri J. Properties of tricalcium silicate sealers. J Endod 2016;42:1529-35.

13. Camilleri J. Investigation of the Properties of a Novel Tricalcium Silicate-Based Sealer; 2016.

14. Prati C, Gandolfi MG. Calcium silicate bioactive cements: Biological perspectives and clinical applications. Dent Mater 2015;31:351-70.

15. Zhou HM, Du TF, Shen Y, Wang ZJ, Zheng YF, Haapasalo M. In vitro cytotoxicity of calcium silicate-containing endodontic sealers. J Endod 2015;41:56-61.

16. Hashieh IA, Pommel L, Camps J. Concentration of eugenol apically released from zinc oxide-eugenol-based sealers. J Endod 1999;25:713-5.

17. Ho YC, Huang FM, Chang YC. Mechanisms of cytotoxicity of eugenol in human osteoblastic cells in vitro. Int Endod J 2006;39:389-93.

18. Yilmaz Z, Dogan AL, Ozdemir O, Serper A. Evaluation of the cytotoxicity of different root canal sealers on L929 cell line by MTT assay. Dent Mater J 2012;31:1028-32.

19. Loushine BA, Bryan TE, Looney SW, Gillen BM, Loushine RJ, Weller RN, et al. Setting properties and cytotoxicity evaluation of a premixed bioceramic root canal sealer. J Endod 2011;37:673-7.

20. Scelza MZ, Linhares AB, da Silva LE, Granjeiro JM, Alves GG. 
A multiparametric assay to compare the cytotoxicity of endodontic sealers with primary human osteoblasts. Int Endod J 2012;45:12-8.

21. Ekwall B, Silano V, Paganuzzi-Stammati A, Zucco F. Toxicicity tests with mammalian cell cultures. In: Short-Term Toxicity Tests for Non-Genotoxic Effects. SCOPE: John Wiley \& Sons Ltd.; 1990. p. 75-96.

22. Corr G, Stockholm D, Paldi A. Non-genetic variability in cell cultures. In: Culture of animal cells. ${ }^{\text {rd }}$ éd. Paris: Lavoisier; 2014. p. 33-42.

23. Berridge MV, Herst PM, Tan AS. Tetrazolium dyes as tools in cell biology: New insights into their cellular reduction. Biotechnol Annu Rev 2005;11:127-52.
24. Bryan TE, Khechen K, Brackett MG, Messer RL, El-Awady A Primus CM, et al. In vitro osteogenic potential of an experimental calcium silicate-based root canal sealer. J Endod 2010;36:1163-9.

25. Dimitrova-Nakov S, Uzunoglu E, Ardila-Osorio H, Baudry A, Richard G, Kellermann O, et al. In vitro bioactivity of Bioroot ${ }^{\mathrm{TM}} \mathrm{RCS}$, via A4 mouse pulpal stem cells. Dent Mater 2015;31:1290-7.

26. Cotton TP, Schindler WG, Schwartz SA, Watson WR, Hargreaves KM. A retrospective study comparing clinical outcomes after obturation with Resilon/Epiphany or Gutta-Percha/Kerr sealer. J Endod 2008;34:789-97. 